\title{
BMJ Global Health Using a population-based survey approach to estimate child separation after a natural disaster: findings from post-Hurricane Haiti
}

\author{
Lindsay Stark, ${ }^{1}$ Matthew MacFarlane, ${ }^{1}$ Beth L Rubenstein, ${ }^{1,2}$ Gary Yu, ${ }^{1,3}$ \\ Celina Jensen, ${ }^{4}$ Katharine Williamson ${ }^{4}$
}

To cite: Stark L, MacFarlane M, Rubenstein BL, et al. Using a population-based survey approach to estimate child separation after a natural disaster: findings from postHurricane Haiti. BMJ Glob Health 2018;3:e000784. doi:10.1136/ bmjgh-2018-000784

Handling editor Seye Abimbola

Received 19 February 2018 Revised 30 April 2018 Accepted 1 May 2018
Check for updates

${ }^{1}$ Department of Population and Family Health, Mailman School of Public Health, Columbia University, New York City, New York, USA

2Department of Epidemiology, Mailman School of Public Health, Columbia University, New York City, New York, USA ${ }^{3}$ Rory Meyers College of Nursing, New York University, New York City, New York, USA ${ }^{4}$ Save the Children, London, UK

Correspondence to Dr Lindsay Stark; Is2302@cumc.columbia.edu

\section{ABSTRACT}

Introduction This study explores findings of a population-based approach to measure the prevalence of unaccompanied and separated children (UASC) during the Hurricane Matthew aftermath in Haiti.

Methods We conducted a cross-sectional survey using two-stage cluster sampling. Participants were asked to provide information on their own household composition, as well as the household composition of their closest neighbour (the Neighborhood Method). The study took place between February and March 2017 in Haiti's Sud Department, a region severely affected by Hurricane Matthew in October 2016. 1044 primary respondents provided information about their own household, and 4165 people in the household of their closet neighbour. The primary outcome measured was the prevalence of UASC in the Sud Department following Hurricane Matthew. Secondary outcomes of interest included the characteristics of these children, including age, sex, reason for separation and current caregiver.

Results Of the 2046 children currently living in the surveyed households, $3.03 \%$ (95\% $\mathrm{Cl} 2.29 \%$ to $3.77 \%$ ) were reported to have been separated from their normal caregiver during Hurricane Matthew. Among these 62 children, 9 were unaccompanied, and there were slightly more boys than girls ( $56 \%$ vs $44 \%, p=0.37$ ). Of the 2060 children who lived in surveyed households when the hurricane hit, $1.12 \%(95 \% \mathrm{Cl} 0.67 \%$ to $1.57 \%)$ had since departed without their caregiver. The prevalence of separation reported for neighbours' households was not significantly different from that in respondents' households ( $p$ values between 0.08 and 0.29 ).

Conclusions This study is the first known attempt to measure the prevalence of child separation following a natural disaster. Overall, the rates of separation were relatively low. Similarities between primary and secondary reports of child separation via the Neighborhood Method indicate that this may be a viable approach to measuring UASC in certain contexts.

\section{INTRODUCTION}

Children often become separated from their parents or other caregivers during humanitarian emergencies due to circumstances

\section{Key questions}

What is already known?

- Children separated from their caregivers in an emergency are vulnerable to various health risks.

- There is no standard practice to obtain a representative estimate of separated and unaccompanied children in an emergency.

\section{What are the new findings?}

- Rates of separation after Hurricane Matthew were low, suggesting that separation is not a uniform phenomenon across emergencies.

- Differing patterns of separation by age and gender are observed, which could influence humanitarian programming and policy response.

What do the new findings imply?

- This study is the first known attempt to measure the prevalence of child separation following a natural disaster, showing that a population-based survey approach is feasible.

such as parental death, food insecurity, migration and poverty. Some separated children are sent to live with relatives, neighbours or friends, while other separated children are left completely without an adult support system (this latter group of children are referred to as 'unaccompanied'). Both separated and unaccompanied children are vulnerable to a number of risks, including health problems, malnutrition, child labour and sexual exploitation. ${ }^{1-6}$ Separated and unaccompanied children also experience more long-term adverse cognitive and mental health outcomes, including depression and anxiety, compared with children who are not separated. $^{7-11}$

The humanitarian community has developed multiple services to mitigate the vulnerabilities faced by unaccompanied and separated children (UASG). Among 
these services, practitioners tend to place the highest priority on implementing family tracing and reunification programmes, designed to return children to their previous caregivers. Such programmes are usually set up in the immediate aftermath of an emergency event. ${ }^{12}$ Yet despite these investments in service provision, there is no standard practice or method to determine a representative estimate of the number of UASC in a humanitarian emergency.

Without a sense of how many children are separated, practitioners must rely on a mix of generalised assumptions and selective information to design and target their activities. In addition, advocates for separated children are limited in their ability to secure funding for this population since they cannot provide donors with accurate information on the scale of the problem. For example, over the past 30 years, most child protection actors have assumed that separated children comprise approximately $3 \%-5 \%$ of the displaced population in an emergency context. ${ }^{13}$ This assumption has never been validated, and, moreover, it ignores the complex nature of emergencies and cultural contexts in which the profile of separation may diverge significantly. Recognising this diversity, the Child Protection Rapid Assessment (CPRA) was designed to gather context-specific information about UASC 6-8 weeks after an emergency event. ${ }^{14}{ }^{15}$ However, the CPRA is a qualitative tool and it is not intended to measure the scale of separation in an affected area.

Ultimately, the lack of representative, population-based data about UASC in humanitarian emergencies presents a challenge for the entire child protection sector. To address this gap, in 2014, the Assessment and Measurement Task-Force of the Global Child Protection Working Group launched an interagency initiative to develop a core set of methods to generate rigorous statistics about UASC across a range of emergency settings. Through a close partnership with an Advisory Panel composed of practitioners, policymakers, and donors, researchers from Columbia University designed an innovative approach to measure the prevalence of separated children in an emergency setting. The approach was first tested in the eastern Democratic Republic of the Congo (DRC) in 2014. ${ }^{16}$

Following the completion of the DRC pilot, a number of key questions and areas for further exploration were identified. First, the Advisory Panel and the research team concluded that differences between chronic emergency situations, such as conflict-affected eastern DRC, and rapid-onset emergencies, such as natural disasters, necessitated a second pilot in a rapid-onset emergency. In addition, questions remained around the appropriateness of the Neighborhood Method for measuring this population. ${ }^{17}$ The Neighborhood Method is built on the assumption that respondents are knowledgeable about their neighbour's household composition and can reliably report on outcomes of interest for nearby households. ${ }^{18} 19$ This approach has the potential to substantially reduce the sample size, time and costs involved in conducting a household survey, if the key assumption can be validated. Finally, challenges in data entry and analysis in the first pilot motivated the methodologists to streamline the forms to maximise efficiency. The present study therefore reports on the methods, findings and implications of a second pilot to estimate the prevalence of UASC in a rapid-onset natural disaster setting using an adapted version of the methods and tools from the DRC. ${ }^{16}$

\section{METHODS \\ Setting}

The second iteration of the population-based estimation tool for UASC was piloted in the Sud Department of Haiti between February and March 2017. Encompassing an estimated 775000 people, with $37 \%$ of the population age 15 years or under, the Sud Department is one of the poorest areas of Haiti and was one of two regions severely affected by Hurricane Matthew in October 2016. ${ }^{20}$ Hurricane Matthew was the strongest hurricane to hit the region in a decade. The storm caused widespread destruction to property, infrastructure, agriculture and livestock and also resulted in a significant death toll. An estimated $90 \%$ of homes in the Southern peninsula (which includes both the Sud and Grand'Anse Departments) were affected, with hundreds of schools damaged or destroyed and more than a million people nationwide in need of assistance..$^{21} 22$

\section{Main sample}

Sampling was achieved via a two-stage cluster design. Assuming precision of $1.5 \%$ and a design effect of two, it was estimated that the study would need 35 clusters of 23 households per cluster to detect a $5 \%$ prevalence of separation. The sample was increased to 28 households per cluster to achieve adequate power with an expected household response rate of $80 \%$.

For the first stage, clusters were sampled at the section level using probability proportionate to size (PPS). PPS calculations were based on 2015 population data from the Haitian Institut de Statistique et d'Informatique. For the second stage, houses within each cluster were selected via systematic random sampling. Using Google Earth satellite images, areas of 90-150 households within each cluster were randomly chosen and all households in the selected area were numbered. A sampling interval $m$ was determined by dividing the total number of households in the selected area by 28 . A random number between 1 and the interval $m$ was used to select the first household. Then every $m$ th household was selected in a systematic fashion to achieve a sample that was distributed across the full area of 90-150 households.

\section{Data collectors}

Two teams of eight data collectors were hired for the duration of the study. All data collectors lived in the Sud Department and had served as community mobilisers with Save the Children after Hurricane Matthew. 
Members of the research team from Columbia University and Save the Children led a 2-week training in French for all data collectors. The training covered topics including the use of tablets and study tools for data collection, research procedures and definitions, and how to identify and respond to urgent action child protection referrals. The data collectors practised their new skills through role plays and field visits.

\section{Study protocol}

Upon reaching a selected household, data collectors asked to speak with the female head of household, or, if she was not available, any other adult woman in the household. If no adult women were available, data collectors asked to speak with any adult man. If no adult was available, data collectors asked to speak with a married woman older than 15 years of age. If no eligible household member was available, the team continued on to the next selected household, but made arrangements to return to unavailable households whenever possible. On the second visit, if there were still no eligible respondents at home or if the respondent declined to participate in the study, the household was marked as a non-response.

Before any interview began, data collectors introduced the study and respondents were asked for verbal consent to participate in the research. Respondents who consented were then invited to create a visual map of their household, which the data collector used to create a household roster. The age and sex of each current household member was also recorded. A household member was defined as someone who slept under the roof of the home for at least five consecutive days each week. Laminated cards were used to facilitate the mapping (see figure 1), allowing the respondent to create a tactile and visual map to aid their own recall.

Once the mapping was complete, data collectors asked respondents whether each current household member was living in the household prior to Hurricane Matthew. The respondent was also asked to indicate the current caregiver for each child, as well as each child's caregiver before the hurricane. If a child's caregiver had changed since the hurricane, a series of additional questions were asked to determine the nature and reason for the change. Questions were also asked about any people who had lived in the household before the emergency, but who were not part of the current roster. Finally, respondents were asked to answer the exact same set of questions about the household of their closest neighbour.

By asking about general household composition before and after the emergency event, rather than separated children in particular, the intent was to reduce bias and avoid the potential of either overestimating or underestimating the true number of UASC. Asking about caregiver differences before and after the emergency also reduced the possibility that the respondents could deliberately misreport separation.

All data were collected on Samsung Galaxy tablets using the SurveyCTO application. Data collection was conducted in Haitian Creole.

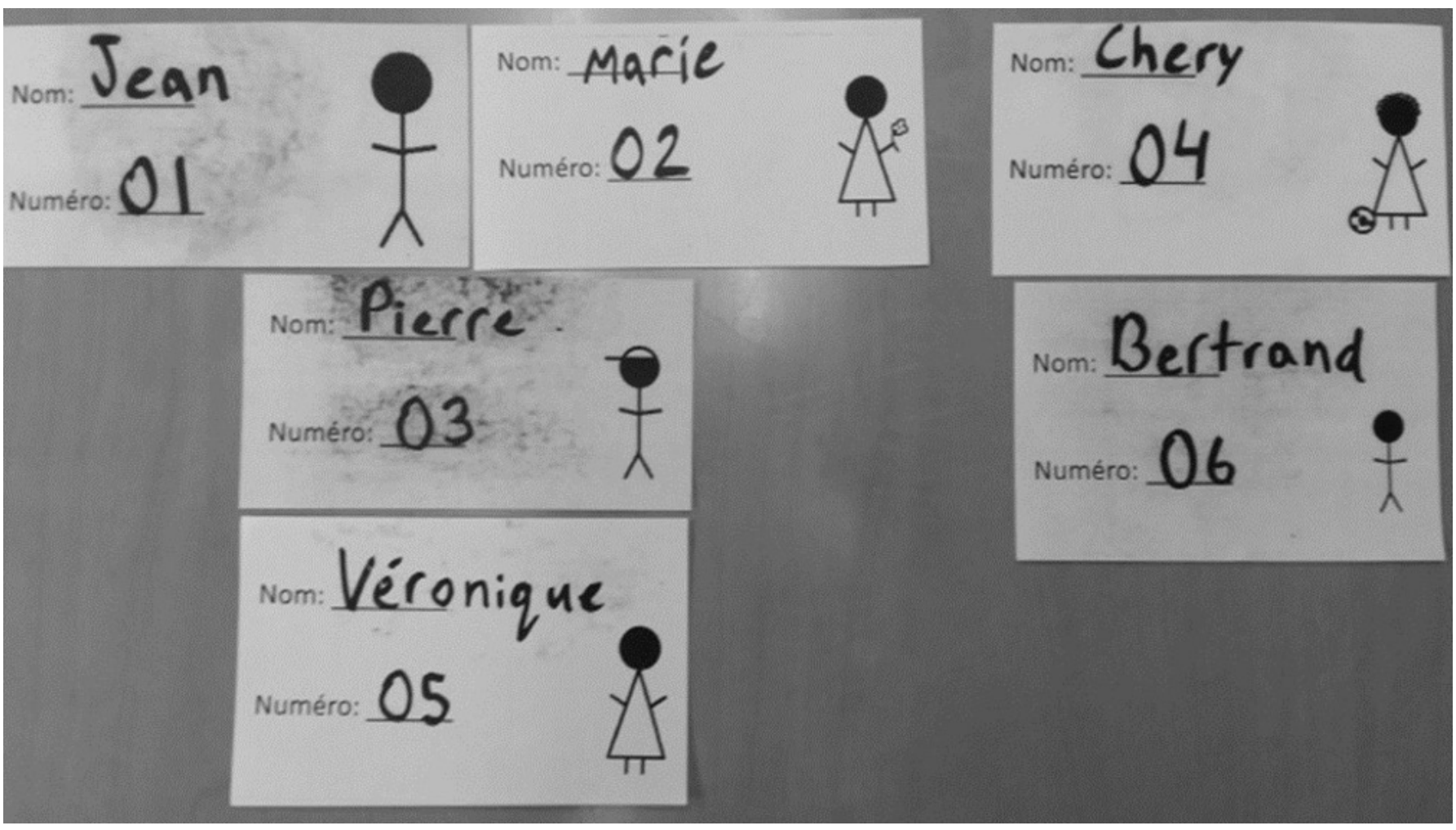

Figure 1 Laminated cards. 


\section{Primary outcomes}

The primary outcome of interest was the prevalence of UASC in the Sud Department in the 5-month period following Hurricane Matthew. The secondary outcome of interest was a profile of the characteristics of these children, including age, sex, reasons for separation and current caregiver.

UASC were defined following the UN Convention on the Rights of the Child. ${ }^{23}$ Separated children were defined as children who have been separated from both parents or from their previous legal or customary primary caregiver, but not necessarily from other relatives. Therefore, the definition includes children under the care of other adult family members. Unaccompanied children were defined as children who have been separated from both parents and other relatives and who are not being cared for by any adult who, by law or custom, is responsible for doing so.

To compensate for the fact that UASC might be living in places not captured by a household survey (such as on the street or in a residential care facility), the tools were designed to measure 'departures' from, as well as 'arrivals' of, children into households. 'Arrivals' were defined as any child who currently lived in the sampled household, but whose caregiver had changed following the hurricane. Thus, arrivals included children whose primary caregiver had changed following the hurricane, but who continued to live in the same location. Arrivals also included new children living in the household who had not lived there prior to the emergency. 'Departures' were defined as children who left the sampled household since the hurricane and whose caregiver had changed, meaning departures did not include children who had left with their primary caregiver. Departures were intended to capture a portion of the population of children who left households to live in residential care settings, on the street or elsewhere. Births and deaths were not counted as arrivals or departures.

\section{Neighbour sample}

In addition to the main sample, a neighbour sample was established by asking all households in the main sample to also provide identical information about the household composition of their closest neighbour. Collecting data about respondents' neighbours is known as the Neighborhood Method and has been used to reduce the sample size, time and costs involved in conducting household surveys. ${ }^{18} 19$ The application of the Neighborhood Method to measurement of UASC was piloted in DRC, but the results suggested the method did not yield reliable data for this topic in that setting. ${ }^{17}$ The research team was interested in testing the reliability of the Neighborhood Method to measure UASC in Haiti, where different emergency dynamics (primarily the acute nature of the hurricane) were hypothesised to potentially improve its reliability. The neighbour sample in Haiti was analysed separately from the main sample and was not included in the power calculation.

\section{Secondary respondents}

While the team hypothesised that female heads of households would be reliable informants about the primary outcomes of interest, the team was interested in testing this hypothesis. In order to assess the reliability of female heads of household compared with other potential respondents, data collectors conducted second interviews with alternative respondents in a small number of households already included in the main sample. Specifically, in each of the 35 clusters, in 2-3 selected households, a second adult woman was interviewed. In an additional 2-3 selected households per cluster, an adult man was interviewed. All interviews were identical to the original interview performed with the female head of household in the same home and both interviews were executed simultaneously.

\section{Statistical analysis}

The prevalence and characteristics of UASC in the main study sample, the neighbour sample and the sample of secondary respondents were calculated using basic frequencies. Statistical differences in the prevalence of separated children and unaccompanied children (1) by primary households and neighbours' households, (2) by primary respondents and secondary respondents within the households and (3) by primary female respondents and primary male respondents within the households were calculated using a two-sample independent z-test for proportions. 95\% CI and affiliated two-sided $\mathrm{p}$ values are reported assuming a Type I significance level of $5 \%$. Weighted prevalence of separated children and unaccompanied children were estimated for primary households and neighbours' households by averaging the stratified prevalence among the 35 clustered sites. The basic demographic characteristics of separated children were compared between arrivals and departures using descriptive frequencies and column percentages.

Arrivals and departures were kept separate in data analysis. One reason for maintaining this division was that respondents did not always know where a departed child was residing. A child could be residing in another household within the sampling universe, in which case she/ he already would be counted in arrivals. Alternately, a departed child could have left the sampling universe altogether. Additionally, it was acknowledged that separated children arriving in homes likely have different characteristics and require different programmatic responses than those departing from homes.

\section{RESULTS}

\section{Household characteristics}

Of 1175 primary households sampled, a total of 1044 households were surveyed-a response rate of $88.5 \%$. The majority of non-participating households did not have eligible respondents at the time of visit or during any follow-up attempt $(n=103,8.77 \%)$, and $2.38 \%(n=28)$ declined to participate. Primary households reported that 
Table 1 Prevalence of separation by primary households and neighbours' households

\begin{tabular}{|c|c|c|c|c|c|c|c|}
\hline & \multicolumn{3}{|c|}{ Primary households } & \multicolumn{3}{|c|}{ Neighbours' households } & \multirow[b]{2}{*}{$P$ values } \\
\hline & $\mathbf{n}$ & Prevalence (\%) & $95 \% \mathrm{Cl}$ & $\mathbf{n}$ & Prevalence (\%) & $95 \% \mathrm{Cl}$ & \\
\hline \multicolumn{8}{|l|}{ Unweighed } \\
\hline \multicolumn{8}{|l|}{ Arrivals } \\
\hline Separation (overall) & 62 & 3.03 & (2.29 to 3.77 ) & 34 & 2.43 & (1.62 to 3.24$)$ & 0.29 \\
\hline Unaccompaniment & 9 & 0.44 & (0.15 to 0.73$)$ & 2 & 0.14 & $(0.00$ to 0.34$)$ & 0.12 \\
\hline \multicolumn{8}{|l|}{ Departures } \\
\hline Separation (overall) & 23 & 1.12 & (0.67 to 1.57$)$ & 5 & 0.48 & (0.06 to 0.90$)$ & 0.08 \\
\hline Unaccompaniment & 0 & 0.00 & (0.00 to 0.00$)$ & 0 & 0.00 & (0.00 to 0.00$)$ & - \\
\hline \multicolumn{8}{|l|}{ Weighted } \\
\hline \multicolumn{8}{|l|}{ Arrivals } \\
\hline Separation (overall) & 35 & 2.93 & (0.00 to 8.52$)$ & 35 & 2.64 & (0.00 to 7.95$)$ & 0.94 \\
\hline Unaccompaniment & 9 & 0.42 & (0.14 to 0.70$)$ & 2 & 0.17 & (0.00 to 0.39$)$ & 0.20 \\
\hline \multicolumn{8}{|l|}{ Departures } \\
\hline Separation (overall) & 35 & 1.30 & (0.00 to 5.05$)$ & 35 & 0.76 & $(0.00$ to, 3.64$)$ & 0.82 \\
\hline Unaccompaniment & 0 & 0.00 & (0.00 to 0.00$)$ & 0 & 0.00 & (0.00 to 0.00$)$ & - \\
\hline
\end{tabular}

they had lived in their current location for an average of 27 years. Mean household size was 6.06 people, including an average of 2.08 children per household.

\section{Prevalence of separation based on primary household data}

Out of a total of 2046 children living in the surveyed households at the time of data collection, $3.03 \%$ of these children $(n=62)$ were reported to have been separated following Hurricane Matthew, meaning they had either arrived in the household after the emergency or experienced a change in caregiver during this time. Among the 62 separated arrivals, 9 children were unaccompanied. Results were robust to weighting across clusters (see table 1).

Among separated children, there were slightly more boys, compared with girls, but this difference was not statistically significant ( $56 \%$ vs $44 \%, \mathrm{p}=0.37)$. Nearly two-thirds of the 62 separated arrivals were between 5 and 14 years of age (see table 2). Before the hurricane, $75 \%$ of these children were under the care of their mothers or fathers. Following the hurricane, the most common caregivers were aunts or uncles $(40 \%)$ and grandparents $(29 \%)$. A notable percentage of arrivals $(8 \%)$ were serving as restaveks or child domestic workers for an unrelated adult and a total of $56 \%$ were unaccompanied. The vast majority of arrivals $(>80 \%)$ were separated intentionally, meaning that there was a decision made by the past caregiver to separate from the child. School was the most common reason for separation $(46 \%)$, followed by death of parents and food insecurity (17\% each).

Out of a total of 2060 children living in the surveyed households prior to Hurricane Matthew, 1.12\% (n=23 children) had since departed from their households without their previous caregiver. Among the 23 separated departures, none were recorded as unaccompanied.
Again, these results were robust to weighting across clusters.

There were slightly more departed girls, compared with boys, but this difference was not statistically significant $(61 \%$ vs $39 \%, p=0.41)$. With the exception of two very young children, all of the departures were between 5 and 17 years of age. Before the hurricane, $65 \%$ of these children were being cared for by their mothers or fathers. After the hurricane, most departed children were thought to be under the care of an aunt or uncle $(57 \%)$ or a grandparent (13\%), but for $17 \%$ of departures, their current caregiver was unknown to the respondent. Nearly every case of separation among departures was reported as intentional $(96 \%)$, with the most common reasons for separation being school (44\%) and death of parents $(31 \%)$.

\section{Neighbour sample}

In total, 1044 primary respondents provided information about 4165 people in the household of their closest neighbour. The prevalence of separated children who arrived in neighbours' households was $2.43 \%$, with a prevalence of $0.79 \%$ for unaccompanied children. The prevalence of separation among departures was $0.48 \%$ (see table 1). These rates were slightly lower, overall, compared with the prevalence of separation reported in the respondents' own homes, but the differences were not statistically significant different at the 0.05 level. This was true for both arrivals $(p=0.29)$ and departures $(p=0.08)$, as well as departing unaccompanied children $(p=0.47)$. However, there was a statistically significant difference in prevalence of separation for unaccompanied arrivals in the neighbour sample compared with the main sample $(\mathrm{p}=0.02)$. 
Table 2 Basic characteristics of separated children

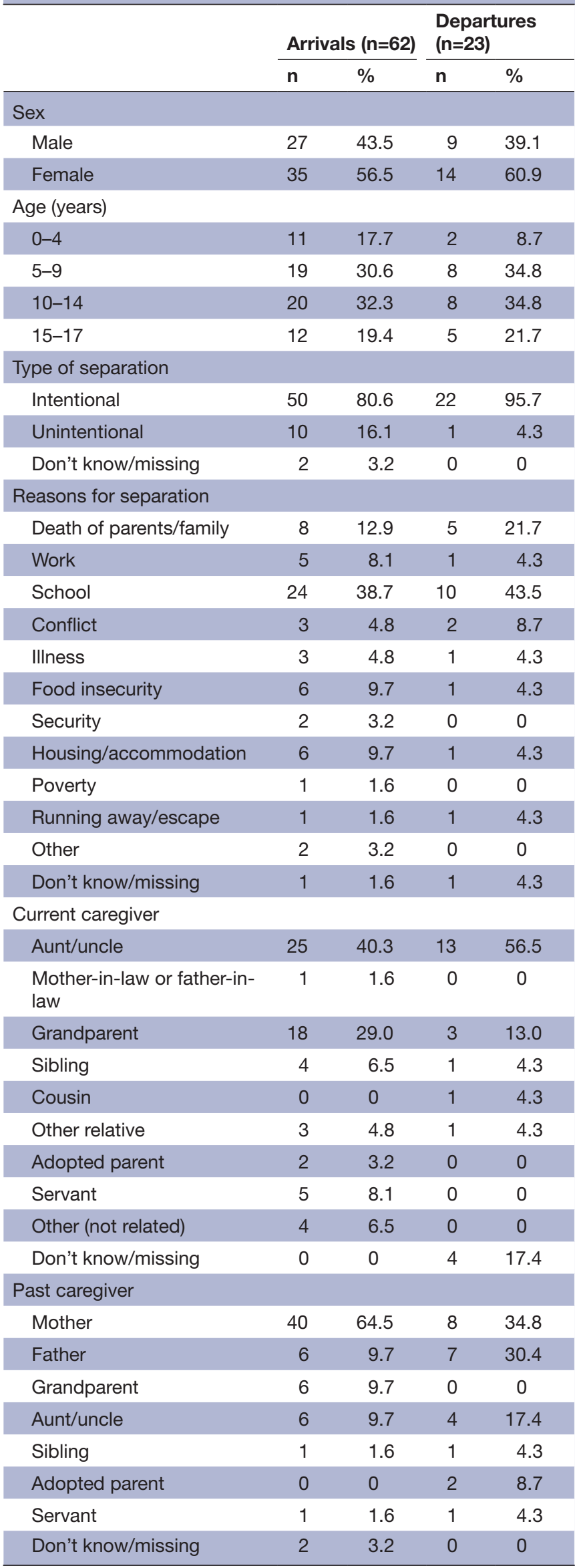

\section{Secondary respondents}

Finally, secondary respondents in a subset of households were compared with the female head of household to determine the level of reliability between different household respondents. Data from 99 secondary adult female respondents and 103 adult male respondents were compared with data from female heads of household from the same homes. The prevalence of separated children reported by the secondary female respondents was $2.97 \%$ for arrivals and $0.44 \%$ for departures compared with $3.64 \%$ and $0.81 \%$ according to the female heads of household. These differences were not statistically significant at the 0.05 level. The prevalence of separation reported by adult male respondents was $5.50 \%$ for arrivals and $1.05 \%$ for departures compared with $4.69 \%$ and $0.47 \%$ according to the female heads of household (see table 3). Again, the differences between the primary and secondary respondents were not statistically significant at the 0.05 level.

\section{DISCUSSION}

These findings from Haiti have important implications for child protection programming following natural disasters. Overall, rates of separation 4 months after Hurricane Matthew were relatively low $(3.03 \%$ for arriving children and $1.12 \%$ for departing children). In the DRC, 18 months after the M23 takeover of Goma, separation was substantially higher $(8.47 \%$ for arriving children and $5.31 \%$ for departing children). Although the numbers from Haiti and the DRC are not directly comparable due to fundamentally different emergency events, different recall periods and different inclusion criteria, the low levels of separation in Haiti illustrate that separation is not a uniform phenomenon across emergencies. ${ }^{16}$

The findings from Haiti also underline the wide variability in rates of separation in different emergencies and call into question the utility of rules of thumb such as the 5\% rule. Rather than being a uniform experience, the prevalence and characteristics of separation are likely informed by a range of contextual factors. For example, in the DRC, physical security concerns related to conflict is an ongoing feature of the emergency, whereas in Haiti, Hurricane Matthew had its largest impact on property, infrastructure and agriculture. The high proportion of intentional separation in Haiti, and the focus on school as a reason for separation, likely reflects these livelihood-related drivers.

From a response perspective, the Haiti data point to the potential for economic strengthening to protect children and families in the wake of a natural disaster. The data also reveal certain groups of children who may be at increased risk of separation in these situations. For example, fathers were identified as the primary caregivers before the hurricane for $30 \%$ of departing children and $10 \%$ of arriving children. This suggests that after natural disasters, prompt and targeted outreach to children under the primary care of their fathers may be 
Table 3 Prevalence of separation across secondary respondents in the same home

\begin{tabular}{|c|c|c|c|c|c|}
\hline $\begin{array}{l}\text { Primary adult } \\
\text { females }(n=95)\end{array}$ & $\begin{array}{l}\text { Secondary adult } \\
\text { females }(n=95)\end{array}$ & D & $\begin{array}{l}\text { Primary adult } \\
\text { females }(n=103)\end{array}$ & $\begin{array}{l}\text { Adult males } \\
(n=103)\end{array}$ & \\
\hline Prevalence (\%) & n Prevalence (\%) & values & Prevalence (\%) & Prevalence (\%) & 5 \\
\hline
\end{tabular}

\begin{tabular}{|c|c|c|c|c|c|c|c|c|c|c|}
\hline \multicolumn{11}{|l|}{ Arrivals } \\
\hline Separation (overall) & 9 & 3.64 & 7 & 2.97 & 0.60 & 10 & 4.69 & 11 & 5.50 & 0.82 \\
\hline Unaccompaniment & 0 & 0 & 1 & 0.42 & 0.31 & 0 & 0 & 0 & 0 & \\
\hline \multicolumn{11}{|l|}{ Departures } \\
\hline Separation (overall) & 2 & 0.81 & 1 & 0.44 & 0.57 & 1 & 0.47 & 2 & 1.05 & 0.54 \\
\hline Unaccompaniment & 0 & 0 & 0 & 0 & & 0 & 0 & 0 & 0 & \\
\hline
\end{tabular}

merited. In addition, children working as child domestic workers (termed restaveks in Haiti) also constituted a large proportion of separations in the sample. There are a number of programmes which are already actively working to reduce the prevalence of restaveks in Haiti and these programmes may benefit from linkages with emergency response efforts.

The findings also have methodological implications. A secondary objective of the study was to evaluate the applicability of the Neighborhood Method to the measurement of UASC. The applicability of the Neighborhood Method to this topic was previously evaluated in the DRC, and, for the most part, the results from neighbours' households were not consistent with the results from respondents' households. ${ }^{16}$ This finding suggested the Neighborhood Method may not be appropriate for measuring UASC. However, given the significant advantages of the Neighborhood Method in terms of time and cost efficiency (compared with a traditional household survey), further evaluation of the method in Haiti was warranted. In Haiti, the prevalence of separation in neighbours' households was generally not statistically significantly different from the prevalence of separation in respondents' households. This finding provides cautious optimism that the Neighborhood Method may be a viable approach to the measurement of UASC in certain contexts, but further testing is needed to see if this result can be replicated. Reliability testing to more directly assess agreement between respondents' reports about their neighbours and neighbours' reports about their own household is also recommended.

In addition, the results from the comparison of prevalence estimates across different respondents within the same household (female heads of household, other adult women and other adult men) suggest that rates of child separation did not differ according to the respondent. Thus, in the future, household surveys about UASC may be able to collect data from a more expansive list of eligible respondents. This would have practical utility in emergency contexts when surveyors are unable to return multiple times to try to find the female head of household.

\section{Limitations}

The study did have several limitations. First, the estimation was not inclusive of the entire area of Haiti affected by Hurricane Matthew. The Grand'Anse department was also devastated by the storm but was not a part of the sampling frame. Poverty in Grand'Anse is more extreme than in Sud, and therefore, Grand'Anse may have experienced higher rates of separation following Hurricane Matthew. Second, while the recall period of 4-5 months in Haiti was an improvement over the recall period of 18 months in the DRC, a lag time of 4-5 months between the emergency event and data collection means that the findings from Haiti must be interpreted as representing longer term and secondary separation, rather than immediate separation. The lag time also means that some of the separations that were reported may have been unrelated to Hurricane Matthew and instead reflect baseline separations in the region, such as separations caused by natural caregiver deaths. Finally, the study likely under-represented separated children living outside of households, such as children living in residential care institutions and children living on the street. Although some of these children may have been captured within departures, the study design systematically excludes children who were living in these situations prior to the emergency event and whose caregiver status was disrupted by the emergency. Different methods and sampling frames are required to estimate separation in these out-of-household populations, and to date, efforts to do so in emergency settings have not been successful. ${ }^{24}$

\section{CONCLUSION}

This study is the first known attempt to estimate the prevalence of child separation in the wake of a natural disaster. The profile of separated children in Haiti following Hurricane Matthew was very different from the profile of separated children in the DRC. The findings from Haiti emphasise the importance of collecting population-based data about local separation patterns whenever possible and avoiding the use of crude, unproven 'rules of thumb' to generalise about separation in a given situation. The methods described here will help researchers generate contextual learning about UASC following future 
emergency events. Representative data on the prevalence and characteristics of these children will provide crucial insights for programmers, policymakers and funders working in child protection. Over time, these data will also contribute to an improved global understanding of how the complex patterns and drivers of separation vary according to different emergency typologies.

Contributors LS, BLR and MMacF designed the study, participated in development of data collection measures, led data interpretation and drafted the manuscript. KW obtained funding. KW and CJ supported field implementation. MMacF and CJ oversaw data collection. MMacF and GY oversaw data entry and analysis. All authors reviewed and provided input to the final manuscript. All authors had full access to all of the data (including statistical reports and tables) in the study and can take responsibility for the integrity of the data and the accuracy of the data analysis.

Funding The study was funded by USAID's Office of Foreign Disaster Assistance.

Disclaimer The funders played no role in the study design; in the collection, analysis and interpretation of data; in the writing of the report; and in the decision to submit the article for publication.

Competing interests None declared.

Patient consent Not required.

Ethics approval This study was covered under Columbia University Medical Center's IRB reference AAAQ6665.

Provenance and peer review Not commissioned; externally peer reviewed.

Data sharing statement Requests for access to the data should be sent to the corresponding author/principal investigator.

Open Access This is an Open Access article distributed in accordance with the Creative Commons Attribution Non Commercial (CC BY-NC 4.0) license, which permits others to distribute, remix, adapt, build upon this work non-commercially, and license their derivative works on different terms, provided the original work is properly cited and the use is non-commercial. See: http://creativecommons.org/ licenses/by-nc/4.0/

(C) Article author(s) (or their employer(s) unless otherwise stated in the text of the article) 2018. All rights reserved. No commercial use is permitted unless otherwise expressly granted.

\section{REFERENCES}

1. Bianchini K. Unaccompanied asylum-seeker children: Flawed processes protection gaps in the UK. Forced Migration Review 2011;73:52-3

2. ICRC. Inter-agency guiding principles of unaccompanied and separated children, 2004.

3. Engle PL, Black MM, Behrman JR, et al. Strategies to avoid the loss of developmental potential in more than 200 million children in the developing world. Lancet 2007;369:229-42.
4. Lay M, Papadopoulos I. Sexual maltreatment of unaccompanied asylum-seeking minors from the Horn of Africa: a mixed method study focusing on vulnerability and prevention. Child Abuse Negl 2009;33:728-38.

5. Mushingeh ACS, Mkandawire A, Nkula M, et al. HIV/AIDS and child labour in Zambia: A rapid assessment on the case of the Lusaka, Copperbelt and Eastern Provinces. Lusaka/Geneva 2002.

6. UNHCR. Through the eyes of a child: Refugee children speak about violence - A report on participatory assessments carried out with refugee and returnee children in Southern Africa. 2005-2007. Geneva, 2007.

7. Bick J, Zhu T, Stamoulis C, et al. Effect of early institutionalization and foster care on long-term white matter development: a randomized clinical trial. JAMA Pediatr 2015;169:211-9.

8. Bronstein I, Montgomery P, Ott E. Emotional and behavioural problems amongst Afghan unaccompanied asylum-seeking children: results from a large-scale cross-sectional study. Eur Child Adolesc Psychiatry 2013;22:285-94.

9. Reed RV, Fazel M, Jones L, et al. Mental health of displaced and refugee children resettled in low-income and middle-income countries: risk and protective factors. Lancet 2012;379:250-65.

10. Van ljzendoorn MH, Bakermans-Kranenburg MJ, Juffer F. Plasticity of growth in height, weight, and head circumference: meta-analytic evidence of massive catch-up after international adoption. J Dev Behav Pediatr 2007;28:334-43.

11. Vanderwert RE, Marshall PJ, Nelson CA, et al. Timing of intervention affects brain electrical activity in children exposed to severe psychosocial neglect. PLoS One 2010;5:e11415.

12. CPWG. Minimum standards for child protection in humanitarian action: CPWG, 2012

13. Ressler EM, Boothby N, Steinbock DJ. Unaccompanied children: care and protection in wars, natural disasters, and refugee movements. Oxford, UK: Oxford University Press, 1988.

14. Ager A, Blake C, Stark L, et al. Child protection assessment in humanitarian emergencies: case studies from Georgia, Gaza, Haiti and Yemen. Child Abuse Negl 2011;35:1045-52.

15. Child Protection Working Group (CPWG). Child protection rapid assessment toolkit: Global Protection Cluster, 2012.

16. Stark L, Rubenstein BL, Mansourian $\mathrm{H}$, et al. Estimating child separation in emergencies: Results from North Kivu. Child Abuse Negl 2016;52:38-46.

17. Mansourian $\mathrm{H}$, Rubenstein BL, Spencer $\mathrm{C}$, et al. Assessing the use of the neighborhood method to estimate the prevalence of child separation: a pilot in North Kivu, DRC. Confl Health 2016;10:17.

18. Stark $\mathrm{L}$, Warner $\mathrm{A}$, Lehmann $\mathrm{H}$, et al. Measuring the incidence and reporting of violence against women and girls in liberia using the 'neighborhood method'. Confl Health 2013;7.1):1.

19. Stark L, Roberts $L$, Wheaton $W$, et al. Measuring violence against women amidst war and displacement in northern Uganda using the "neighbourhood method". J Epidemiol Community Health 2010;64:1056-61.

20. ACAPS. Haiti: Hurricane Matthew Department Profile, Sud, 2016.

21. Migration IOf. Haiti - Hurricane Matthew Situation Report \#9, 2016.

22. Programme WF. Haiti Hurricane Matthew Situation Report \#04, 2016.

23. UNICEF. Convention on the rights of the child: UNICEF, 1989.

24. Rubenstein BL, MacFarlane M, Jensen C, et al. Measuring movement into residential care institutions in Haiti after Hurricane Matthew: A pilot study. PLoS One. In Press. 2018;13:e0195515. 